\section{Multiple myeloma presenting as cervical spine compression}

\author{
Makram Frigui, ${ }^{1}$ Faten Frikha, ${ }^{1}$ \\ Hanene Haj Kacem, ${ }^{1}$ Zaher Boudawara, ${ }^{2}$ \\ Tahia Boudawara, ${ }^{3}$ Zouhir Bahloul ${ }^{1}$ \\ 1Department of Internal Medicine, Hédi \\ Chaker Hospital, Sfax; ${ }^{2}$ Department of \\ Neurosurgery, Habib Bourguiba Hospital, \\ Sfax; ${ }^{3}$ Department of Pathology, CHU \\ Habib Bourguiba Hospital, Sfax, Tunisia
}

\begin{abstract}
Multiple myeloma (MM) is a malignant monoclonal proliferation of plasma cells usually showing bone involvement with predilection of the spine. The cervical spine is the least common site of disease involvement. We report the case of 72-year-old man presenting with progressively increased cervical pain, associated with sciatica and disturb walking. In the neurological exam, there was a quadripyramidal syndrome, and superficial sensory disturbance. The $\mathrm{X}$ - ray examination of the cervical spine showed lytic lesions of $\mathrm{C} 2$. A tumoral process was found by magnetic resonance imaging (MRI) compressing the spinal cord at the level of $\mathrm{C} 4$ with osteolysis of the posterior arch. An open surgery was performed. Microscopic examination and immunohistochemical studies confirmed the diagnosis of multiple myeloma of kappa subtype. Immunoelectrophoresis revealed the presence of immunoglobulin G kappa. The patient was diagnosed as having MM with cervical vertebra involvement and he has started chemotherapy.
\end{abstract}

\section{Introduction}

Multiple myeloma (MM) is a malignant monoclonal proliferation of plasma cells which represents $1 \%$ of all cancers and $10 \%$ of haematological malignancy. ${ }^{1,2}$ Because of the distribution of haematopoietic cells, the spine is one of the most commonly affected sites, either by a diffuse osteoporosis induced by an increase in pro-inflammatory cytokines or by focal osteolytic lesions. ${ }^{1}$ Spinal compression can be the initial clinical presentation of the disease in 34$64 \%$ of the patients, leading to pain or neurological complications. ${ }^{3}$ The involvement of the cervical spine is not as common as in the thoracic and lumbar spine; nonetheless, it can lead to severe neurological complications. ${ }^{4}$

We report an unusual case of Ig $\mathbf{G}$ multiple myeloma presenting with cervical spinal compression.

\section{Case Report}

A 72-year-old male patient was referred to our department in March 2007 with a 2-week history of neck pain, lower and upper extremities weakness. Physical examination found a stiff cervical spine. His neurological examination revealed quadripyramidal syndrome, superficial sensory disturbance at the level of the forth cervical vertebra (C4) and urinary troubles. Biological abnormalities consisted of: sedimentation rate $135 \mathrm{~mm} / \mathrm{h}, \mathrm{C}$-reactive protein 82 $\mathrm{mg} / \mathrm{dl}$, haemoglobin $9.6 \mathrm{~g} / \mathrm{dl}$. White cell count, platelet count, serum creatinine, calcaemia were within the normal range. The $\mathrm{X}$ - ray examination of the cervical spine showed lytic lesions of C4 (Figure 1). Spinal magnetic resonance imaging (MRI) showed an epidural mass compressing the spinal cord at the level of $\mathrm{C} 4$ with osteolysis of the posterior arch (Figure 2). The patient underwent an open surgery consisting of C3-C4 laminectomy, resection of the tumor, decompression of the spinal cord reconstruction and stabilisation of the vertebral column. Postoperatively, the examination showed the improvement of neurological deficit and of sensory disturbance. Microscopic examination and immunohistochemical studies confirmed the diagnosis of multiple myeloma of kappa subtype. The protein electrophoresis of the blood and urine, showed the presence of a paraprotein (monoclonal protein type IgG) band, with reduction of the other (normal) immunoglobulins. Serum immunoglobulin (Ig) levels were as follows: Ig G: $56 \mathrm{~g} / \mathrm{L}$; IgA: 0,69 g/L and IgM : 0,5 $\mathrm{g} / \mathrm{L}$. The Bence Jones protein was positive (type kappa light chains). The bone marrow aspiration showed infiltration with $45 \%$ of plasma cells. The diagnosis of IgG MM with kappa light chains, stage IIIB according to the DurieSalmon staging system was made. The patient started systemic Vincristine, Melphalan, Cyclophosphamide and Prednisone (VMCP) combination chemotherapy. Currently, he received 18 cycles of chemotherapeutic regimen and showed a complete response. The bisphosphonate Zoledronic acid was also administrated at the same time. During the follow up the general condition of our patient was well and he had complete relief of pain. The clinical examination was normal and he showed no residual neurological deficit.

\section{Discussion}

In the present case, the presence of a tumoral mass in the spinal cervical vertebra at $\mathrm{C} 4$ with signs of cord compression led to surgical decompression. Surprisingly, the aetiology of this solid tumor was found to be MM. In the literature, spinal compression in patients with
Correspondence: Faten Frikha, Department of Internal Medicine, Hédi Chaker Hospital, Sfax 3029, Tunisia. Tel: +216.98657098 .

E-mail: fetenfrikha@yahoo.fr

Key words: multiple myeloma, cervical spinal cord compression, magnetic resonance imaging.

Received for publication: 5 June 2011.

Revision received: 20 July 2011.

Accepted for publication: 22 July 2011.

This work is licensed under a Creative Commons Attribution NonCommercial 3.0 License (CC BYNC 3.0).

(C) Copyright M. Frigui et al., 2011

Licensee PAGEPress, Italy

Rheumatology Reports 2011; 3:e5

doi:10.4081/rr.2011.e5

MM is not rare, occurs in 55-70\%, especially in the lower thoracic or lumbar vertebral bodies. ${ }^{4}$ However, the cervical spine seems to be involved less often and spinal cord compression following vertebra fractures or vertebra plasmocytomas comprises 5\% of the presentations of MM. ${ }^{5,6}$ Between 1993 and 2005, 35 patients with MM of the cervical spine were identified. ${ }^{7}$ The most common manifestation was pathological fractures of C2. ${ }^{7}$ Myeloma cells, which invade the marrow spaces of the spine, induce secretion of osteoclast-activating factors, including interleukins. These interleukins result in production of tumor necrosis factors, which promote further osteolysis. ${ }^{89}$ Spinal cord compression is usually caused by primary involvement

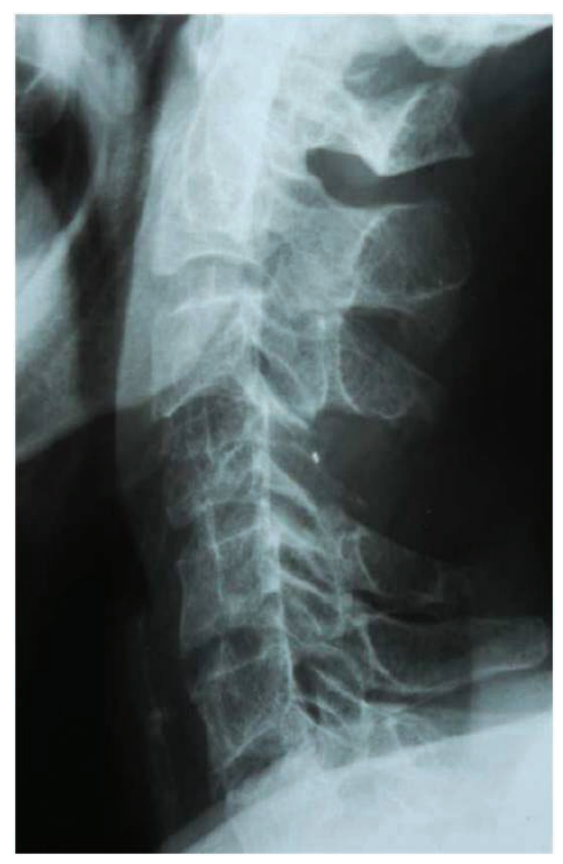

Figure 1. X-ray examination of the cervical spine: lytic lesions of C4. 


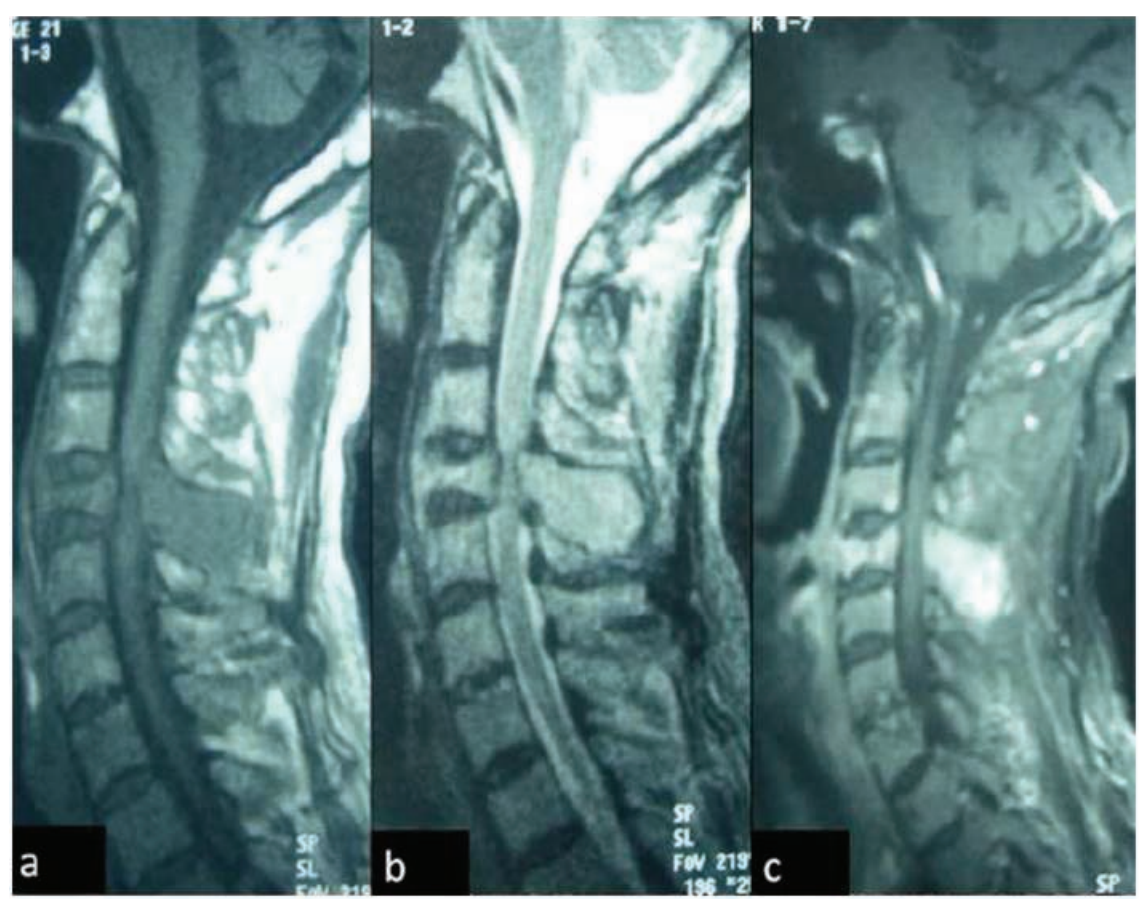

Figure 2. Magnetic resonance imaging of cervical spine (a) T1 ponderation, (b) T2 ponderation, (c) Ti ponderation after Gadolinium injection): cervical spine compression at the level of C4 with osteolysis of the posterior arch.

of the vertebral body with tumor extension into the adjacent spinal canal. ${ }^{10}$ The authors think that spinal involvement may be caused by extension of paraspinal lymph node into the intervertebral foramen. ${ }^{10}$ Others suggested that the tumors can originate from lymphoid tissue present in the epidural space. ${ }^{11}$

Bone dissolution caused by myeloma may rapidly lead to pain, spinal instability, kyphotic deformity, and spinal cord compression as a result of epidural extension of the disease. ${ }^{7}$ MRI has been established as a sensitive method in detecting localised or diffuse bone lesions in MM.10,12 The aspect of the spinal involvement in MRI is similar to patients with spinal metastases. However, MM must be suspected whenever the MRI shows focal mass, multiple focal masses in the axial skeleton, diffuse marrow involvement, or the presence of multiple compressive fractures in patients without known history of primary cancer. ${ }^{2}$ In our case, MRI demonstrated cervical spinal cord compression due to a separate extensive epidural mass in the cervical spinal canal.

The treatment of choice of MM is chemotherapy, but the response to such treatment in the presence of extramedullary lesions is very poor. ${ }^{13}$ Treatment options for cervical spine involvement often involves radiation therapy and surgical methods (laminectomy for decompression, stabilization), associated with bed rest, bracing, bisphosphonates, and analgesics. Indications for radiation therapy include radiosensitive tumors, expected survival of less than 3-4 months, poor patient health, total neurological deficit, or diffuse spinal disease. In a retrospective review, the authors showed that patients with MM metastatic to the cervical spine may benefit from radiotherapy, even in the presence of radiographically documented instability. ${ }^{7}$ They confirm that radiation therapy for long term palliation of pain is very effective in this localization. However, in the context of spinal instability or neurological deficit from cord compression, surgical intervention is usually warranted. ${ }^{7}$

For surgery, indications include treatment for radioresistant tumor, spinal cord compression, progressive neurological deterioration, previous radiation therapy and spinal instability. ${ }^{7}$ For our patient, the signs of cord compression with neurological deficit led to emergent surgical treatment. In this situation, circumferential surgical decompression and stabilization has been advocated as providing a significant benefit. ${ }^{9}$

The median survival of patients with myeloma is approximately 2.5 years, although this rate appears improved to approximately 4.5 years in the younger patients. With spinal involvement, $75 \%$ of patients die within 1 year of diagnosis while almost all die within 4 years. ${ }^{14}$ In our case, the patient underwent surgery with C3-C4 spine decompression (laminectomy C3-C4), and was started chemotherapy for myeloma. During the follow up study, the back pain was reduced significantly. Thirty six months after the beginning of treatment, the patient is still alive and did well.

\section{Conclusions}

Cervical spine cord compression can be the first presentation of Multiple Myeloma and should bear in mind the rare possibility of the disease. Treatment should include surgical resection and local radiation therapy, as the response to conventional chemotherapy of extramedullary multiple myeloma is considered very poor.

\section{References}

1. Mundy GR. Myeloma bone disease. Eur J Cancer 1998;34:246-51.

2. Angtuaco EJ, Fassas AB, Walker R et al. Multiple myeloma: clinical review and diagnostic imaging. Radiology 2004; 231:11-23.

3. Cotten A, Boutry N, Cortet B. Multiple myeloma. In: Mathis JM, Deramond H, Belkoff SM (eds) Percutaneous vertebroplasty. New York: Springer, 2002; pp 134137.

4. Lecouvet FE, Vande Berg BC, Maldague BE. Vertebral compression fractures in multiple myeloma. Part I. Distribution and appearance at MR imaging. Radiology 1997;204: 195-9.

5. Kyle RA, Gertz MA, Witzig TE, et al. Review of 1027 patients with newly diagnosed multiple myeloma. Mayo Clin Proc 2003;78:2133.

6. Chakraborti C, Miller K. Multiple myeloma presenting as spinal cord compression: a case report. JMCR 2010;4:251.

7. Rao G, Ha CS, Chakrabarti I et al. Multiple myeloma of the cervical spine: treatment strategies for pain and spinal instability. J Neurosurg Spine 2006;5:140-5.

8. Barille-Nion S, Bataille R. New insights in myeloma-induced osteolysis. Leuk Lymphoma 2003;44:1463-7.

9. Hjertner 0 , Standal T, Borset M, et al. Identification of new targets for therapy of osteolytic bone disease in multiple myeloma. Curr Drug Targets 2005;6:701-11.

10. Palmbach M, Hoffmann W, Grodd W, et al. Extraosseous, epidural tumor spread of multiple myeloma. Eur J Radiol 1996;22:146-8.

11. George ED, Sadovsky R. Multiple myeloma: recognition and management. Am Fam Physician 1999;59:1885-94.

12. Bataille R, Harousseau JL. Multiple myeloma. N Engl J Med 1997;336:1657-64.

13. Damaj G, Mohty M, Vey N, et al. Features of extramedullary and extraosseous multiple myeloma: a report of 19 patients from a single center. Eur J Haematol 2004;73:402-6.

14. Tashjian RZ, Bradley MP, Lucas PR. Spinal epidural hematoma after a pathologic compression fracture: an unusual presentation of multiple myeloma. Spine J 2005;5:454-6. 